\title{
ARTIGO
}

\section{A INFÂNCIA, O BRINCAR E O JOGAR: REFLEXÕES A PARTIR DO REFERENCIAL TEÓRICO DE NORBERT ELIAS}

\author{
Vinicius Machado de Oliveira - (https://orcid.org/0000-0003-1789-8243) * \\ Universidade Estadual de Maringá, Maringá, Paraná, Brasil \\ Juliano de Souza - (https://orcid.org/0000- 0003-3491-9536) * * \\ Universidade Estadual de Maringá, Maringá, Paraná, Brasil
}

\begin{abstract}
RESUMO: A fase em que se estabelece a infância é um período essencial na vida dos seres humanos, não só para o desenvolvimento físico e cognitivo como também social. Contudo, apesar do reconhecimento desta importante etapa do desenvolvimento humano, estudos sob o ponto de vista sociológico têm sido pouco explorados na literatura. Partindo deste cenário e sabendo então da necessidade de mais estudos sobre essa temática no campo educacional, o presente texto tem como objetivo contextualizar o papel da infância e de suas atividades, tais como o brincar e o jogar, no contexto do processo civilizador. Palavras-chave: Infância; Brincadeira; Jogo; Processo Civilizador.
\end{abstract}

\section{CHILDHOOD, PLAYING AND TOYING: REFLECTIONS FROM NORBERT ELIAS' THEORETICAL REFERENCE}

ABSTRACT: The childhood phase is an essential period to people's lives, not only for the physical and cognitive development but also to the sociocultural development. However, despite the recognition of this important stage of human development, social studies about this subject have not been explored with intensity in academic literature. Starting from this scenario and acknowledging the need for further studies on this subject in the educational field, this paper aims to contextualize the role of childhood and its activities, such as to play and to toy in the context of the civilizing process.

Keywords: To toy; Excitement; Children; Play; Norbert Elias.

\footnotetext{
* Graduado em Educação Física pela Universidade Estadual do Centro-Oeste (UNICENTRO). Aluno de Mestrado do Programa de Pós-Graduação Associado em Educação Física UEM/UEL - Universidade Estadual de Maringá (UEM). Membro do Observatório de Educação Física e Esporte (OEFE).

E-mail:<oliveira_vm@hotmail.com>

** Doutor em Educação Física pela Universidade Federal do Paraná (UFPR). Professor do Programa de Pós-Graduação Associado em Educação Física UEM/UEL - Universidade Estadual de Maringá (UEM). Coordenador do Observatório de Educação Física e Esporte (OEFE).

E-mail:<julianoedf@yahoo.com.br >.
} 


\section{INTRODUC̣̃̃O}

A área que estuda a infância sob uma perspectiva sociológica global está em desenvolvimento na literatura, sendo natural que a temática ainda seja incipiente e com inúmeras lacunas cujas quais, pouco a pouco, vão sendo preenchidas através dos esforços dos pesquisadores. Apesar do aumento de estudos ${ }^{1}$ da infância nas últimas décadas associados a várias frentes de investigação, ainda parece notável que tenhamos poucas respostas sobre a posição da infância na sociedade, pois quanto mais o tecido social se complexifica, mais difícil se torna o preparo para o processo civilizador individual ${ }^{2}$ das crianças (ELIAS, 2012).

Assim, compreender os pequenos é o primeiro exercício para situar e descortinar o papel da infância no seio da sociedade. Todavia, descobrir as crianças em sua essência socialmente constituída, não significa compactuar com a ideia que são meros "adultos pequenos"; muito pelo contrário, uma abordagem do ponto de vista da sociologia dos processos ${ }^{3}$ permite entender que elas se tornam adultas, individualmente, por meio dos processos de civilização, referentes à amplitude de desenvolvimento de cada sociedade/nação/Estado (ELIAS, 2011; ELIAS, 2012).

Assim sendo, quanto mais complexas as demandas e as exigências das funções na sociedade adulta, maior é a lacuna entre o comportamento das crianças e adultos e, por conseguinte, mais difícil e mais longo o processo de civilização individual a se percorrer, o que, inevitavelmente, demanda uma maior preparação das crianças para as funções adultas (ELIAS, 1994). Diante desta realidade, as crianças são expostas desde tenra idade a um rígido conjunto de regras para desenvolver autocontrole sobre seus impulsos e atitudes.

Deste modo, assim como os adultos de outrora, embora em uma magnitude talvez maior, as crianças que ingressam num estágio seguinte do processo civilizador ${ }^{4}$ têm problemas sensíveis com as pulsões que foram e são suprimidas em meio às rotinas de seriedade das sociedades modernas. Não por acaso, portanto é que, em uma escala mimética, as pessoas basicamente precisam de atividades que estimulem as tensões que não são permitidas nas rotinas de seriedade. Dentro desta perspectiva, na realidade das crianças, mas também de adultos, as brincadeiras, jogos e, posteriormente, os esportes permitem, por assim dizer, uma negociação mimética de conflitos sociais sublimados (SOUZA, 2014) ou, noutros termos, possibilitam um extravasamento de tensões e pulsões sociais deixados para trás em virtude do avanço civilizatório. 
Tais atividades, nessa perspectiva, são as primeiras formas da criança estabelecer relações sociais com os outros e exercitar sua capacidade de viver no mundo insuflado de conflitos. Além disso, essas práticas, de alguma forma, preparam as crianças para as fases subsequentes da vida, mesmo que de forma lúdica e fantasiosa. Essa, inclusive, é a hipótese que permeia nossa argumentação.

Sabendo então da importância da infância para o desenvolvimento do indivíduo bem como das potencialidades das brincadeiras e dos jogos na vida dos infantes, este texto tem por objetivo discutir tais temáticas do ponto de vista da sociologia dos processos, com base nas contribuições de Norbert Elias, autor que, no corpo de sua obra, apresentou elementos para uma "sociologia da infância" que embora tenha sido pouco explorada por ele próprio ao longo de sua trajetória intelectual é motivo de discussão e desenvolvimento sistemático na literatura (DIAS, 2013; TOZZI, 2013; SARAT, 2014; CRUZ; SARAT, 2015).

Para levar a cabo nossos objetivos, estruturamos o texto em três seções. Na primeira parte, revisitamos a infância de Norbert Elias, procurando identificar elementos dessa fase de sua vida que, de maneira ou outra, influenciaram sua trajetória acadêmica e intelectual. Já na segunda seção, exploramos as contribuições do referencial teórico de Norbert Elias para contextualizar o advento da infância sob o ponto de vista sociológico. Por fim, localizamos o papel das brincadeiras e dos jogos na formação da criança, dialogando com a literatura e também com o referencial teórico do sociólogo alemão.

\section{TRAÇOS DA INFÂNCIA DE NORBERT ELIAS POR ELE MESMO}

A infância é período crucial na vida dos seres humanos, pois essa fase influi no desenvolvimento subsequente do indivíduo (SARAT, 2014) do ponto de vista físico, cognitivo e social. No caso de Elias, não há dúvidas que sua infância teve papel fundamental em suas realizações, inclusive, acadêmico-científicas. Sob esse enfoque, sua infância, repleta de experiências, apresenta elementos para melhor situarmos o autor no contexto de seu próprio tempo, permitindo recuperar alguns aspectos que podem ter sido motivadores para sua carreira de professor e sociólogo.

Norbert Elias nasceu em 22 de junho de 1897 em Breslau, uma cidade polonesa tomada pela Alemanha (ELIAS, 2001a). Em 1900, Breslau de aproximadamente 500 mil habitantes, era abundante em recursos e bens, sendo cercada por uma rica região agrícola. Apesar de ter uma origem polonesa, o local em nada possuía traços que se podia 
dizer da Polônia. Pelo contrário, a região era totalmente germanizada e até os mais poloneses falavam intimamente o alemão (ELIAS, 2001a).

Elias (2001a) descreve com detalhes o local em que vivera durante a infância e, inclusive, revela os primeiros ambientes e crianças com o qual costumava brincar. Era morador de um prédio de dois andares que ficava situado na esquina de uma rua. Esse prédio dava de frente para um canal em que as pessoas costumavam patinar no inverno. Próximo ao apartamento havia um parque com bancos e árvores, em que as crianças iam brincar, inclusive o próprio Elias. Os excertos a seguir revelam mais desses aspectos:

Assim, em frente à casa, tínhamos uma vista muito bonita, muito peculiar, e no inverno - todos os invernos, que me lembre - a água dos fossos congelava e as pessoas patinavam. Era essa a vista movimentada que tínhamos, e, as vezes, eu também ia patinar no gelo (ELIAS, 2001a, p. 12).

“[...] as pessoas que encontrávamos no parque eram bem diferentes umas das outras. Viam-se muitas crianças levadas por governantas, e eu também ia bastante, para brincar de bambolê ou outros jogos com as demais crianças (ELIAS, 2001a, p. 12).

As crianças que tivera contanto e brincava com maior regularidade eram os filhos da zeladora que moravam no porão do prédio. "A gente descia lá embaixo, em um pequeno apartamento, e era lá que viviam as crianças com as quais eu costumava brincar: uma menina e um menino que andavam descalços no verão" (ELIAS, 2001a, p. 12). Ele não relata que tipos de brincadeiras faziam ou que brinquedos utilizavam, mas depreende-se que eram essas as crianças que Elias estivera mais socializado na infância.

Norbert Elias foi o filho único de pais judeus, radicados em Breslau, advindos do movimento migratório da comunidade judaica. O pai era do ramo têxtil, como muitos dos judeus da época, e a mãe não trabalhava, mas administrava as atividades sociais da casa, tais como os compromissos que a família possuía em meio as outras, que também gozavam de uma condição econômica semelhante.

Apesar de ser filho único, Elias tinha preceptoras, cujas quais, grosso modo, preenchiam a lacuna da falta de irmãos. Contudo, mesmo assim quando indagado se gostaria de ter tido irmãos, ele demonstrou certa simpatia com a ideia, mesmo que essa vontade não se manifestasse quando criança. "Todavia, ainda mantenho a convicção de que é bom que as crianças não cresçam do jeito que cresci, e suponho que isso queira dizer que teria adorado ter irmãos e irmãs, mesmo que tal desejo tenha permanecido inconsciente" (ELIAS, 2001a, p. 16).

Logo nos primeiros anos de idade escolar, enfrentou diversas dificuldades com a educação, não porque era mau aluno, mas sim, 
porque era uma criança com a saúde muito frágil e que adquiria facilmente qualquer doença característica da infância. Esta situação fazia com que não fosse possível frequentar a escola assiduamente, tendo os pais que conseguirem aulas particulares sobre o intermédio do diretor da sua escola (ELIAS, 2001a).

Desde muito novo, era um exímio adepto à leitura e tinha contato com diversos tipos de livros. Fascinava-se pela literatura alemã e seus autores clássicos como Goethe, Schiller, Eichendorff, entre outros, textos que pareciam muito avançados para apenas uma criança, mas que eram de interesse dele (ELIAS, 2001a). Tal literatura, de acordo com Elias, foi uma das matrizes que também ajudaram a desenvolver sua teoria geral da sociedade:

Ainda hoje, o papel desempenhado pela literatura alemã clássica em minha formação inicial, que se exprimia através do orgulho que eu sentia de ter esses livros e pelo fato de haver mergulhado muito cedo nessa literatura, me parece determinante. É a literatura alemã, entre outras, que devo a extensão e a profundidade de minha abordagem dos problemas humanos (ELIAS, 2001a, p.95).

Assim, entre os 6 e 7 anos de idade já se considerava trabalhando em um projeto que um dia iria se materializar em sua dedicação à docência e à pesquisa. Porém, na realidade que vivia em Breslau era inconcebível a ideia de um judeu ocupar uma cátedra em uma universidade alemã. Mas mesmo em um cenário permeado por dificuldades, sua perseverança não o deixaria desistir do sonho de ensinar e pesquisar. "Soube isso desde minha primeira infância, e trabalhei tenazmente para atingir esse objetivo, mesmo que as vezes me parecesse impossível" (ELIAS, 2001a, p. 22).

Contudo, ainda que sua determinação fosse maior que as adversidades que enfrentara ao longo de sua carreira, Norbert Elias não nega que o período da infância, sobretudo o da fase escolar, não fora fácil, tendo em vista que o discurso antissemita e xenofóbico aumentava na sociedade alemã, inclusive entre as crianças que começavam a expressar tal habitus. ${ }^{5}$ Nessa esteira, Elias aponta que os seus colegas se comportavam agressivamente diante da sua ideia de ser professor, advertindo-o que nunca poderia adotar essa profissão. Esse tipo de postura se manifestou em uma das apresentações escolares de Elias, quando um dos seus colegas de classe advertiu: "O caminho que leva a esta carreira te foi barrado desde o nascimento. Grandes risadas do professor e, claro, de toda a classe" (ELIAS, 2001a, p. 19). Na verdade, a fala do colega de Elias já assinalava fortes indícios que o preconceito contra os judeus começava a ser sistematicamente introjetado na cultura germânica.

Esse preconceito vivenciado por Elias, certamente deixou marcas durante a sua infância, mas como era muito jovem não sabia 
lidar com a situação e não estava preparado para interpretar aquele contexto de exclusão. Somente décadas mais tarde, por meio de seus empreendimentos na área sociológica, é que Elias pôde devolver luz a essas experiências e compreender que o povo judeu era um grupo outsider ${ }^{6}$ na Alemanha, e que ele próprio se enquadrava nessa dinâmica (ELIAS, 2001a). O excerto a seguir reforça essa compreensão:

\footnotetext{
A imagem que remonta mais distante em minha infância é a de uma sociedade de outsiders que, conscientes da igualdade legal e econômica de que gozavam como cidadãos alemães, buscava em grande parte dissimular para si própria sua exclusão no plano social (ELIAS, 2001a, p. 140)
}

Estas experiências decorrentes de atitudes antissemitas, cujas quais vivenciara desde criança, possivelmente podem ter contribuído ainda mais a aguçar o seu interesse pela sociologia, visto que ao crescer em uma sociedade atravessada por problemas se sentiu convidado a refleti-los e compreendê-los. Ademais, a retomada de seu processo civilizador individual, constituído em referência ao local onde morava, às pessoas que convivia, às coisas que lia quando pequeno, às experiências negativas que vivenciara etc., revela elementos importantes do ser humano e do sociólogo que se tornou.

Em síntese, a entrevista concedida a Van Voss e Van Stolk no corpo do livro "Norbert Elias por ele mesmo", que retrata fases da vida do sociólogo, entre elas, a infância, apresenta elementos que remetem às influências desse período nas etapas seguintes da vida do autor, principalmente na escolha de sua profissão e nas opções teóricometodológicas que fizera ao longo de sua vida, conforme lembra Sarat (2014).É possível ainda que essas experiências do pequeno Elias, tenham sido determinantes para que dedicasse atenção especial à forma com que as crianças no seio de suas primeiras interdependências passavam a ingressar no trem cego do processo civilizador.

\section{A INFÂNCIA COMO UM PROBLEMA SOCIOLÓGICO}

A infância é uma fase do desenvolvimento humano marcada por características que permitem singularizar crianças de adultos (SARAT, 2009), sendo, por sua vez, papel dos adultos contribuírem na formação destes agentes, dado seu maior grau de autonomia e independência. Contudo, apesar da balança de poder pender mais para os adultos, Elias ressalta que a criança também tem poder sobre os seus pais, desde que estes na condição de responsáveis, atribuam-lhe algum valor (ELIAS, 2008). Isto parece claro em um exemplo rotineiro, 
quando a criança chora porque está com fome, pois através do choro ela pode de maneira coercitiva expressar que precisa de algo, e logo, se esta criança simboliza algo para eles, os mesmos se prontificarão a resolver as necessidades da criança. Por seu turno, mesmo que instintivamente e numa linguagem que lhe é própria nos primeiros anos de vida, a criança mostra que possui certo grau de poder sobre os pais quando necessitam de algo, e assim sucessivamente no decorrer da infância, enquanto não se emancipa como indivíduo adulto.

Durante o nascimento, as crianças podem ser muito diferentes umas das outras, sobretudo, no que concerne ao seu aspecto natural. Todavia, é apenas no convívio com a sociedade que a criança pequena, através do seu comportamento mais flexível, pode se tornar um ser socialmente mais complexo (ELIAS, 1994), com mais peculiaridades e diferenças em relação a seus pares interdependentes. Assim, é na relação com outros seres humanos que o infante transforma suas faculdades mentais de modo a operacionalizá-la como um adulto. Sem estas relações, ele não consegue alcançar esta outra etapa, podendo desenvolver-se fisicamente, mas ainda apresentando a autonomia psicológica de uma criança pequena (ELIAS, 1994).

[...] é a teia de relações sociais em que vive o indivíduo durante a fase mais impressionável, a infância e juventude, que se imprime em sua personalidade em formação, tendo sua contrapartida na relação entre suas instâncias controladoras, o superego e o ego, e os impulsos da libido. O equilíbrio resultante entre essas instâncias controladoras e as pulsões, em grande variedade de níveis, determina como a pessoa se orienta em suas relações com outras, em suma, determina aquilo que chamamos, segundo o gosto, de hábitos, complexos ou estrutura da personalidade. Não obstante, não há fim ao entrelaçamento, porque embora a autodeterminação da pessoa, maleável durante o início da infância, se solidifique e endureça à medida que cresce, ela nunca deixa inteiramente de ser afetada pelas relações mutáveis com outras durante toda a vida (ELIAS, 1993, p. 205).

A partir disso, tanto o grau quanto o padrão de individualidade de cada adulto só são determinadas mediante as relações que orientam a trajetória social do indivíduo. Desta forma, a estrutura da sociedade em que ele cresce em consonância com os laços familiares, projeta as especificidades enquanto ser humano adulto. É através então da historicidade ${ }^{7}$ que cada indivíduo constitui desde a infância que é possível melhor compreender a sociedade (ELIAS, 1994), em uma relação na qual o indivíduo não pode ser lido isoladamente da sociedade, assim como a sociedade não pode ser desvelada sem o entendimento do indivíduo (ELIAS, 2006). Elias verificou essa relação no âmago do processo civilizador ocidental, demonstrando que o percurso individual de cada pessoa desde a tenra infância alterava o padrão social no decorrer dos séculos. 
Dessa constatação, nosso autor foi além e, como desdobramento teórico, apontou, que na medida em que o processo civilizador era posto em marcha, a distância entre o comportamento das crianças em relação aos adultos aumentava, tendo em vista que o desenvolvimento psicológico dos indivíduos acendia exponencialmente, de modo que as condutas e os comportamentos dos infantes se desligavam de maneira equivalente ao seu desenvolvimento individual para a vida adulta (ELIAS, 2011).

Todavia, quando se atinge a idade adulta, isso não quer dizer que a pessoa está completamente desligada da criança que foi um dia, mas pelo contrário, ela pode carregar o que Elias entende como "resíduos da infância". Isso acontece porque o padrão social que é exigido de um adulto, acaba por suprimir e transformar alguns dos impulsos de quando era criança, muito embora certos desejos possam permanecer a exemplo da vontade de brincar, coisa que, com frequência, é vista como algo estranho em meio as premeditadas rotinas de seriedade dos adultos. Vale salientar que Elias não se refere especificamente ao caso da brincadeira, mas em um exercício de abstração, acreditamos que adultos podem sim apresentar inúmeros "resíduos infantis" que, por ora, podem serem bloqueados ou despertos.

Nesse contexto, uma criança só pode ser entendida como ser humano quando interage com um grupo, de modo que se desprovida destas relações, não há um desenvolvimento sólido do indivíduo. É então através deste grupo e de outros que vão lhes sendo apresentados ao longo da vida, que a criança vai aprendendo a linguagem ${ }^{9}$ para se comunicar e assimilar as regras de controle de pulsões e dos afetos que ditam o processo de civilização. A aquisição destas características não só é essencial para interação com os outros, como também indispensável para a sobrevivência e existência individual (ELIAS, 1998).

Cabe sublinhar que as figurações nas quais as crianças desenvolvem a linguagem nada mais são que as relações sociais que grupos de seres humanos interdependentes estabelecem uns com os outros diante do exercício de convivência em sociedade, lembrando que essas figurações podem ser alteradas conforme os processos e desenvolvimento social (KOURY, 2013). Ademais, tais figurações podem abranger desde unidades mais simples como a família, a escola, a aldeia até os agrupamentos mais complexos como Estado (ELIAS, 2008). Nesse aspecto, a linguagem só é desenvolvida através das relações com essas figurações.

Podemos dizer então que a linguagem que a criança assimila é uma das primeiras camadas sociais ${ }^{10}$ que constituem o indivíduo. É somente por meio do domínio da linguagem que circunda a 
comunicação do grupo em que a criança está inserida, que ela passa a se humanizar, pois sem a assimilação desta instituição (linguagem), ela não consegue efetivamente gozar da multiplicidade de conhecimentos específicos de seu grupo e nem posteriormente na relação com outras pessoas (ELIAS, 1998). Assim sendo, a linguagem é uma das primeiras estruturas que permitem a expressão do habitus, somada evidentemente às relações familiares que inicialmente a engendram.

A propósito, no livro "Os estabelecidos e os outsiders", Elias argumenta sobre o papel da instituição familiar na formação da criança. Os processos grupais constituídos pelos membros da família, caracterizado pela relação pai-mãe-filho, entre outros, são decisivos na constituição do tipo de comportamento e das funções de autocontrole na primeira infância, que são de total importância em meio às exigências das atuais sociedades (ELIAS, 2000). No entanto, após esse período de formação atrelado para a balança "nós", o sujeito começa a se individualizar cada vez mais, funcionando de maneira mais independente, e a balança tendendo mais para o "eu" (ELIAS, 1994).

Outra variável que intervém na vida do indivíduo de forma categórica é o fator "tempo". Este símbolo social que sincroniza e açambarca as relações na sociedade é imposto às crianças desde muito cedo, incutindo na vida dos infantes um sistema de autodisciplina em caráter de coerção que se prolonga ao longo da vida em sociedade (ELIAS, 1998).

Se no decorrer de seus primeiros dez anos de vida, ela não aprender a desenvolver um sistema de autodisciplina conforme a essa instituição, se não aprender a se portar e a modelar sua sensibilidade em função do tempo, ser-lhe-á muito difícil, se não impossível, desempenhar o papel de um adulto no seio dessa sociedade (ELIAS, 1998, p. 14).

Portanto, nas sociedades em que vivemos a regulação temporal é determinante na coexistência dos indivíduos uns aos outros, já que sem essa familiarização com o tempo, o indivíduo está propriamente deslocado do vínculo social ou, melhor dizendo, do contexto diferenciado com extensão prolongada das cadeias de interdependência.

Além dos fatores "tempo", "família", "linguagem" abordados por Elias em sua obra e que, como vimos, são influentes na formação da criança, há outros intervenientes que devem ser levados em consideração na leitura dos infantes, tal como o papel da escola enquanto instituição educacional. Em meio à sociedade em que vivemos, na qual o uso da força física é veementemente condenado, existem outras maneiras de coerção, que tem por finalidade a educação. Dessa forma, a escola com suas imposições de regras é 
um sistema intimamente direcionado ao controle e autocontrole da criança, buscando direcioná-la ao compasso da sociedade (SARAT, 2014). Assim sendo, quanto mais nos civilizamos, mais instituições vão sendo empregadas na formação do indivíduo e mais prolongados e complexos os processos se tornam (ELIAS, 1998). Nas páginas seguintes, continuamos a explorar esses elementos, mas desta vez a partir da retomada dos atos de brincar e jogar na infância.

\section{O BRINCAR E O JOGAR: A BUSCA DA EXCITAÇÃO NA INFÂNCIA}

Está claro na literatura entre as diversas especialidades que se destinam a compreender a infância, que o ato de brincar e jogar são elementos favoráveis e que demarcam uma série de implicações positivas na vida das crianças. Tais atividades são consideradas importantes para o desenvolvimento da criança em múltiplas dimensões e contribuem substancialmente para as fases subsequentes da vida (CHICON et al., 2016; SURDI; MELO; KUNZ, 2016; LEITE; FEIJÓ; CHIES, 2016).

Entre os diversos benefícios que estão associados ao desenvolvimento da criança, além dos aspectos físicos e cognitivos, defendidos com rigor na literatura (MITRE; GOMES, 2004; GINSBURG, 2007; SCALHA et al., 2010; TEIXEIRA, 2017), as brincadeiras e os jogos são atividades que representam outras vantagens ao público infantil, tais como o exercício das relações socioculturais, tão importantes nas sociedades vigentes, e nas quais as redes de interdependências recíprocas são dinâmicas e indispensáveis para a construção de um indivíduo mais autônomo.

Ademais, tais atividades relativamente distanciadas das responsabilidades do cotidiano, podem, em certa medida, tornar menos traumático o processo de formação social das crianças. Nesse caso, brincadeiras e jogos podem reproduzir em pequenas escalas, situações de tensão e pressão, que cotidianamente os adultos se deparam em suas rotinas. Não sem sentido, essas atividades são importantes para preparar as crianças para as demandas mais complexas que lhes serão apresentadas no decorrer da vida.

Por conseguinte, tais demandas se complexificam em função do aumento da especialização nas sociedades modernas, que tornam mais difícil e prolongado a preparação das crianças e jovens para a fase adulta (ELIAS, 1994). Dito de outra forma, quanto mais proporção ganha esse cenário de diversificação das carreiras profissionais, mais demorado e complexo se torna o processo de formação para 
o desempenho das tarefas adultas (ELIAS, 1994). Além disso, com a instauração de uma sociedade gradualmente mais instável, o que Beck (2010) denomina como "sociedade de risco", as pressões e coerções sobre as pessoas aumentam, sobretudo a cobrança sobre os indivíduos mais jovens que requerem um maior preparo para o enfrentamento dessas dificuldades.

Então, estar apto a suportar o ríspido processo de formação social das sociedades modernas, cujas quais instilam sobre os infantes o medo e a ansiedade relativos à perda de oportunidades, é condição essencial para ter êxito no decorrer do processo civilizador individual (ELIAS, 1993). Em outras palavras, as crianças são inculcadas desde muito cedo a atenderem as expectativas de pais e educadores, que transferem todas suas angústias e ansiedades pelo êxito social aos pequenos (ELIAS, 1993). Dessa forma, atividades como brincadeiras e jogos, além de atenuarem esse rígido processo de formação, podem criar ambientes favoráveis para o exercício de gerência desses sentimentos que são instilados pelas nossas sociedades cada vez mais complexas.

Dito de forma mais categórica, é por meio então das brincadeiras, dentro da amplitude da racionalidade e da fantasia das crianças, que é concedido a elas, a oportunidade de descobrirem as relações existentes entre os homens, ou melhor, é por meio destas atividades com caráter lúdico que elas podem vivenciar mimeticamente as atividades dos adultos, se apropriando dos códigos culturais e de papéis sociais, mesmo que de forma simbólica (CORDAZZO; VIEIRA, 2007). Assim, a criança, dentro do seu imaginário, pode reproduzir estas situações em suas brincadeiras.

É oportuno frisar que o termo mimese ${ }^{11}$ foi amplamente utilizado por Elias no intuito de se referir aquelas atividades que possuem caráter de imitação e, por seu turno, autorizam a externalização de pulsões do plano emocional que, em alguma medida, foram suprimidas ou pulverizadas das rotinas de seriedade durante o avanço do processo civilizador (ELIAS, DUNNING, 1992). Nesse particular, em meio as sociedades industriais como as nossas, cuja excitação foi sendo exponencialmente reduzida, as atividades miméticas propiciam um ambiente criado para o controle descontrolado das emoções, sem, no entanto, romperem com o código de comportamento estabelecido no tecido social.

De acordo com Elias e Dunning (1992), atividades miméticas de divertimento, dentre as quais podemos incluir jogos e brincadeiras, têm potencial para reproduzir e criar sentimentos análogos aos desencadeados em situações reais da vida, tais como perigo 
imaginário, medo, tristeza, alegria, prazer etc. Assim, não é destituído de lógica o argumento de que essas atividades podem preparar as crianças para conviverem melhor com esses eventos durante a fase adulta. Ademais, o quadro imaginário proposto pelas brincadeiras e jogos, permite aos infantes vivenciarem em escala microssocial os sentimentos supracitados, sem serem expostos aos verdadeiros riscos e ameaças que, por sinal, colocam em prova a fragilidade humana.

Nesse sentido, não podemos esquecer também a importância dos brinquedos ou de objetos que auxiliam nessa apropriação inventiva que as crianças fazem da vida adulta com suas rotinas de seriedade. De acordo com Kishimoto (2008), o brinquedo é um estimulante material que pode contribuir na fluidez do imaginário infantil. Contudo, nem sempre a criança irá reproduzir fielmente uma ação de acordo com a finalidade do brinquedo, podendo ela atribuir outros significados mediante a sua imaginação (BARROS, 2009). Por exemplo, um brinquedo como o lego, que possui peças para montar, pode permitir à criança contemplar a sua criatividade, tanto na representação mimética de um contexto real como na produção de um mundo totalmente fictício com algum fundo de possibilidade. Isso foi verificado no estudo de Barros (2009), quando observara as atividades na educação infantil, na qual as crianças brincando com peças de montar, reproduziam inúmeras coisas, tais como robôs, castelos, museus etc. Isto é, o brinquedo serviu como um mediador para o ato de brincar e como desdobramento para a brincadeira.

Não obstante essa leitura, o brinquedo, já pode vir com um sistema forte de representações e significados, transcendendo os limites do campo do entretenimento e servindo como ferramenta de controle e regulação no espaço (LIRA; NASCIMENTO, 2015). Deste modo, o âmbito social moderno, gerido por padronizações, pode por meio do brinquedo, imputar mecanismos de controle e subjetivação das crianças ao permitir que valores ocidentais influenciem em questões como gênero, raça, etnia e ideologias em geral (LIRA; NASCIMENTO, 2015). Isso sugere que a representação do brinquedo também pode ser tendenciosa na brincadeira, mesmo que a criança tente impor outros significados ao objeto ou à atividade. Por sinal, tal como sugere Vygotsky: "A situação imaginária de qualquer forma de brinquedo já contém regras de comportamento, embora possa não ser um jogo com regras formais estabelecidas a prior"' (VYGOTSKY, 1994 p.124).

Assim, ainda que notados os potenciais problemas incutidos nas atividades lúdicas - trata-se do brinquedo, das brincadeiras com a inserção do papel social ou então dos jogos simbólicos numa complexidade de tarefas que incluem o brincar de boneca, de 
carrinho, de médico etc. ou os tradicionais, pular corda, amarelinha, pega-pega etc. - essas podem exercer funções significativas durante o desenvolvimento dos infantes, estimulando-os de uma maneira lúdica a intermediarem sua convivência social, de modo a administrarem problemas, resolverem conflitos, exercitarem as relações sociais, organizarem ideias, em um conjunto amplo de novas competências, que vão sendo acumuladas com vistas a prepararem o público infantil para a convivência no plano social (BARROS, 2009).

Vale ressaltar ainda, que a brincadeira e brinquedo estão associados ao contexto e à cultura em que os infantes estão inseridos (DORNELLES, 2001). Logo, ambos têm relação com o momento histórico e com as atividades socialmente mais amplas. Visto por esse ângulo, atividades como as brincadeiras sofrem uma grande influência do meio social no qual as crianças estão inseridas, podendo determinar a forma com que elas interagem umas com as outras, bem como a finalidade que é atribuída a cada brincadeira ou brinquedo.

Nessa esteira, Elias (2012) traz um exemplo interessante que ilustra esta relação da brincadeira ou jogo com o contexto macro. No texto "A civilização dos pais", o autor então se reporta à rotina de uma família de esquimós, em que o meio de sobrevivência é subsidiado pela caça. Nesse espaço social, que difere das sociedades industriais, as crianças esquimós são treinadas desde pequenas a ajudarem na manutenção do grupo. Os meninos, por exemplo, aprendem brincando a manusear o arco com flechas e manejar os barcos, atividades que são intimamente essenciais para desenvolver as habilidades necessárias à caça. As meninas aprendem desde muito novas a trabalharem com a pele de modo a confeccionarem roupas e tendas, também necessárias a subsistência do grupo. Assim tais atividades, embora de forma mais lúdica, visam preparar o esquimó para as competências exigidas na fase adulta.

Em linhas gerais, é brincando pelo "faz de conta" que as crianças podem vivenciar situações do cotidiano e transportarem o mundo adulto para o seu contexto, conhecendo a realidade de outro ângulo e dentro do limite de sua compreensão (CHICON et al., 2016). Mais do que isso, é através do ato de brincar e se movimentar que a criança estabelece as primeiras relações consigo mesma, com os outros e com o mundo em uma escala mais autônoma (CASTRO; KUNZ, 015), o que sugere que as relações em teias de interdependência começam desde a infância conforme assinala Elias em sua obra.

Por conseguinte, com o passar dos anos e com o amadurecimento do indivíduo, a criança vai se racionalizando e as fantasias que eram habituais nas brincadeiras vão dandolugar a atividades mais estruturadas, 
tais como o jogo que necessita de maior organização com um sistema de regras que garanta a sua funcionalidade. De acordo com Vygotsky (1994), toda situação imaginária contém regras, mesmo em nível mais simples próximo às brincadeiras, se bem que à medida que a criança se desenvolve, o jogo de regras ocultas evolui para o jogo de regras mais bem demarcadas. Esse clima mais estruturado desta atividade contribui para que as crianças interajam entre si, vivenciem "situaçõesproblema", formulem estratégias, aprendam com os erros e acertos etc. (CORDAZZO; VIEIRA, 2007) e, mais que isso, exercitem o convívio social a partir dos conflitos que ocorrem durante o momento de jogo.

Dentro dessa perspectiva, Vygostky (1994) é incisivo ao argumentar que os jogos nem sempre proporcionam prazer às crianças, já que os jogos competitivos só tendem a produzir essa sensação quando o resultado se apresenta favorável à criança. Deste modo, como o jogo é um ambiente mais controlado e cheio de regras, a criança tem o seu agir espontâneo mais limitado, fazendo com que ela, muitas das vezes, aja de uma forma contrária à que gostaria de agir (VYGOTSKY, 1994), condição que reduz as propriedades de prazer do jogo em detrimento do resultado. Em contrapartida, esta expectativa que antecede ou sucede o resultado, pode ser o elemento responsável por aumentar o interesse das pessoas no jogo, aumentando as doses de tensão-excitação, conforme Elias sinaliza em seus estudos sociológicos do esporte (SOUZA, 2014).

Vygostky parece confirmar essa relação ao situar os jogos atléticos e ponderar que o desfecho dessas atividades está, de fato, em perder ou ganhar, chegar em primeiro ou último. Durante uma corrida, por exemplo, a criança pode estar em um alto nível de agitação, mas ao ser ultrapassada, o prazer pode diminuir consideravelmente. Assim, ainda que exista a possibilidade de frustração pela derrota ou algo que diminua os níveis de satisfação com a atividade, o objetivo ou propósito do jogo é mais forte. A ausência desse sentido, segundo Vygotsky (1994), equivaleria a uma criança examinar um doce, colocálo na boca, mastigá-lo e cuspi-lo na sequência. Sob esse ponto de vista, simplesmente correr por correr, sem uma finalidade qualquer, pode ser entediante e pouco atrativo para a criança, mesmo que o jogo controlado por regras seja tenso e agudo (VYGOTSKY, 1994). Ademais, conforme sugerem Elias e Dunning (1992) é o clímax gerado por essas tensões do jogo que favorece a excitação.

Além disso, é importante mencionar que, de modo geral, as atividades de divertimento, sejam elas brincadeiras, jogos, esportes ou outras ocupações de lazer, têm como função no tecido social permitirem 
um contrabalanço entre as excitações desagradáveis e o stress provocado pelas demandas da sociedade vigente (ELIAS; DUNNING, 1992). Não obstante, essas atividades, por meio de situações miméticas combinadas a uma excitação agradável, permitem recriar ambientes controlados de descontrole das emoções, sem ferir os códigos de conduta imbricados na sociedade com o avanço do processo civilizador.

Nesse sentido, tanto as brincadeiras quanto os jogos ou esportes têm por finalidade maior construírem uma atmosfera próxima da realidade. Através destas atividades é possível externalizar sentimentos que durante o processo de civilização passaram a ser condenados ou reprimidos, mas que ainda de forma residual estão presentes em nossa natureza, de modo que estamos sempre buscando situações que nos exponham a certas doses de excitação-tensão em ambientes controlados e com menor risco possível (ELIAS; DUNNING, 1992).

Todavia, por mais controlado que sejam tais atividades, é difícil não ocorrerem conflitos ou uma exposição de tensão em demasia que exiba maior agressividade dos indivíduos. É natural, por exemplo, observarmos crianças brincando ou jogando em harmonia e instantes depois discutindo ou trocando pontapés. Embora, isso seja conduta condenável, o tratamento atribuído socialmente à criança é diferente porque se considera que ela não possui maturidade suficiente, em muitos casos, para discernir as implicações morais de seus atos, não sendo, portanto, censuradas de imediato, diferentemente do que acontece quando adultos adotam tais comportamentos e são rotulados de infantis (ELIAS; DUNNING, 1992).

Só as crianças saltam e dançam com excitação, apenas estas não são censuradas de imediato como descontroladas ou anormais, se choram e soluçam publicamente, em lágrimas desencadeadas pelos seus sofrimentos súbitos, se entram em pânico num medo selvagem, ou se cerram os punhos com firmeza e batem ou mordem o odiado inimigo, num total abandono quando se excitam. Ver homens e mulheres adultos agitarem-se em lágrimas e abandonarem-se as suas amargas tristezas em público, ou entrarem em pânico dominados por um medo selvagem, ou a bateremse uns aos outros de forma selvagem debaixo do impacte da sua excitação violenta, deixou de ser encarado como normal (ELIAS; DUNNING, 1992, p. 103).

Com o passar do tempo, as estruturas de personalidade dos indivíduos foram orientadas para a pacificação, incutindo uma relutância e uma profunda repugnância em relação ao uso da violência física (ELIAS, 1997). Assim, por mais zangados que estejamos, somos convidados no âmago de nossa autorreflexão a não agirmos de maneira displicente, diferentemente do público infantil ainda em formação e que não possui, portanto, total jurisdição sobre o seu 
autocontrole. Talvez, por isso, vejamos com certa recorrência o uso de brincadeiras e jogos tão violentos entre escolares.

Dessa forma, quando Elias argumenta que o indivíduo constrói sua história a partir das experiências que ele vivencia ao decorrer de sua vida, certamente podemos dizer que os jogos e as brincadeiras têm sua contribuição no desenvolvimento do indivíduo, em especial porque através de situações como essas, o sujeito, de forma mimética, pode reproduzir em diferentes níveis aspectos estruturantes da realidade. Mas não se reduz a isso e é possível verificar relações mais profundas nestas atividades, tais como a exposição a sentimentos como alegria e satisfação, outro campo de discussão que Norbert Elias também avança quando discorre sobre o lazer e o esporte.

De acordo com Elias e Dunning (1992), atividades que estimulam o prazer podem estar presentes até mesmo entre as crianças de colo. Deste modo, desde a tenra infância, somos colocados em situações que possam originar excitação. Um exemplo que os autores recorrem para defenderem o argumento se materializa na figura de um adulto que embala um bebê. Esta ação, sugerem os autores, pode ter um efeito calmante e produzir uma sensação agradável na criança. Esse efeito que é produzido por movimentos rítmicos repetitivos, pode, inclusive, ser considerado como uma das primeiras formas de excitação da criança.

E o que dizer então, quando um pai lança uma criança para cima e prontamente acolhe ela em segurança em seus braços. Para a mãe essa atitude pode ser intimamente assustadora, porém para a criança é natural que ela sinta algum prazer e excitação nesta atividade, ainda que esta experiência esteja ligada ao medo e ao perigo (ELIAS; DUNNING, 1992).

À medida, contudo, que o indivíduo cresce durante a sua infância ele vai somando outras experiências ao seu repertório social a partir de brincadeiras, jogos e do contato com o esporte. Como muitas atitudes são repreendidas e controladas nas sociedades modernas em virtude do avanço do processo de civilização, atividades miméticas insurgem como antídoto para produzirem tensão-excitação agradável. Talvez seja possível dizer que esse repertório de atividades constitui parte importante do habitus social dos indivíduos desde tenra idade, quer dizer da construção da identidade-eu e da identidade-nós, sendo, entretanto, necessário, mais pesquisas, inclusive de orientação empírica, para conclusões mais peremptórias.

\section{CONSIDERAÇÕES FINAIS}

Ao revisitarmos sistematicamente o conjunto da obra eliasiana foi possível observar que o sociólogo alemão empreendeu, mesmo 
que não tenha sido esse o conteúdo fulcral de suas investigações, uma sofisticada análise social da infância, analisando com rigorosidade os aspectos sociais que essa fase representa na vida dos seres humanos. Interessante notar, que o debate empreendido sobre a infância não aparece apenas em uma ou outra obra, mas sim em vários textos e momentos da produção do autor, que habilitam e consubstanciam o seu referencial para os estudos relativos à sociologia da infância. Dito isso, há muito ainda o que se explorar na obra deste autor sobre o assunto.

Ademais, conforme pudemos argumentar com base no referencial teórico de Norbert Elias, a infância é um período de muita relevância no desenvolvimento do indivíduo, tendo em vista que essa pode influir diretamente na fase adulta. Nesse contexto, são as relações e as experiências que vão sendo conferidas às pessoas desde a infância, que possibilitam a aquisição de camadas sociais, que são indispensáveis para a convivência com os outros. Contudo, à medida que essas camadas vão sendo adquiridas e as relações de interdependência multiplicadas, a pessoa vai se individualizando, construindo sua própria biografia, o que não implica em dizer que ela se desligue das relações sociais, mas ao contrário, que essas relações se tornam mais dinâmicas e presentes em sua vida.

Dessa forma, uma criança só pode ser considerada um ser humano racional quando exposta às redes de interdependência e quando começa a adquirir as camadas sociais constitutivas de seu habitus (sua segunda natureza). Por isso, existe uma grande distância entre adultos e crianças, pois essas ainda em formação, não possuem um arcabouço extenso de experiências e nem tampouco um background suficiente de conhecimentos. Porém, desde muito cedo, em muitas sociedades, a criança é treinada para conviver com os outros e respeitar uma série de normativas, que visam controlar impulsos indissociáveis a uma conduta civilizada.

Em contrapartida, existem atividades que são realizadas desde a infância e que permitem externar sentimentos e emoções que foram lançadas em segundo plano nas nossas rotinas de seriedade durante o processo civilizador. Entre essas atividades se encontram as brincadeiras e os jogos que, como vimos, são atividades essenciais para o desenvolvimento da criança, não sendo somente atrelado ao amadurecimento físico e cognitivo, mas também ao estimulo das relações socioculturais.

Frente a esse cenário, as brincadeiras, os jogos e esportes funcionam como atividades pedagógicas adequadas que possibilitam negociar, em escala mimética, uma série de tensões do cotidiano. A brincadeira no seu estado mais lúdico contribui para que as crianças 
estabeleçam uma relação com o mundo concreto, mesmo que no limite da compreensão delas. Os jogos e esportes, por sua vez, permitem, através de ambientes controlados por regras, resolvermos contendas e problemas, além de estimularem a reflexão e o autocontrole. Em suma, o ato de brincar e jogar é um revigorante exercício de convívio social.

\section{REFERÊNCIAS}

ARIÈS, P. História social da infância e da família. Tradução de Dora Flaksman. Rio de Janeiro: LCT, 1978.

BARROS, F. C. O. M. de. "Você sabe como a gente brinca? De mamãe, de pega-pega, de escolinha, de médico, de neném..." - a teoria histórico-cultural: o brincar como atividade essencial para o desenvolvimento infantil. In BARROS, F. C. O. M. de (org.). Cadê o brincar? da educação infantil para o ensino fundamental. São Paulo: Cultura Acadêmica, p. 103-134, 2009.

BOURDIEU, P. Esboço de uma teoria da prática. In: ORTIZ, R. (org.). A sociologia de Pierre Bourdieu. São Paulo: Olho d’Água,p. 39-72, 2003.

CASTRO, F. B. de; KUNZ, E. O controle da subjetividade e das experiências corporais sensíveis: implicações para o brincar e se-movimentar da criança. Motrivivência. Florianópolis, v. 27, n. 45, p. 44-57, 2015.

CHICON, J. F.; HUBER, L. L.; ALBIÁS, T. R. M.; SÁ, M. das G. C. S. de; ESTEVÃO, A. Educação física e inclusão: a mediação pedagógica do professor na brinquedoteca. Movimento. Porto Alegre, v. 22, n. 1, 279-292, jan./mar. 2016.

CORDAZZO, S. T. D. ; VIEIRA, M. L. A brincadeira e suas implicações nos processos de aprendizagem e de desenvolvimento. Estudos e Pesquisas em Psicologia. Rio de Janeiro, v. 7, n. 1, p. 92-104, 2007.

CRUZ, G. A.; SARAT, M. História da infância no Brasil: contribuições do processo civilizador.Educação e Fronteiras On-Line, Dourados, v. 5, n. 13, 19-33, jan./abr. 2015.

DIAS, S. da C. As contribuições de Norbert Elias para a compreensão da emergência do debate sociológico da infância. Criar Educação, v. 2, n. 2, p. 1-21, 2013.

DORNELLES, L. V. Na escola infantil todo mundo brinca se você brinca. In: CRAIDY, C.; KAERCHER, G. E. P. da S. (org.). Educação Infantil: Pra que quero? Porto Alegre: Artemed, p.101-108, 2001.

ELIAS, N. A civilização dos pais. Revista Sociedade e Estado. Brasília, v. 27, n. 3, p. 469$493,2012$.

ELIAS, N. A sociedade dos indivíduos. Tradução de Vera Ribeiro. Rio de Janeiro: Jorge Zahar, 1994.

ELIAS, N. Escritos e ensaios: 1. Estado, processo, opinião pública. Rio de Janeiro: Jorge Zahar, 2006.

ELIAS, N. Introdução à sociologia. Tradução de Maria Luísa Ribeiro Ferreira. Lisboa: Edições 70, 2008. 
ELIAS, N. Introdução: Sociologia e história. In: ELIAS, N. (org.). A sociedade de corte. Tradução de Pedro Süssekind. Rio de Janeiro: Jorge Zahar, p. 27-60, 2001 b.

ELIAS, N. Mozart: Sociologia, de um gênio. Tradução de Sergio Goes de Paula. Rio de Janeiro: Jorge Zahar, 1995.

ELIAS, N. Norbert Elias por ele mesmo. Tradução de André Telles. Rio de Janeiro: Jorge Zahar, 2001a.

ELIAS, N. O processo civilizador: Formação do Estado e civilização. v. II.Tradução de Ruy Jungmann. Rio de Janeiro: Jorge Zahar, 1993.

ELIAS, N. O processo civilizador: uma história dos costumes. Tradução de Ruy Jungmann. 2. ed. Rio de Janeiro: Jorge Zahar, 2011.

ELIAS, N. Os alemães. A luta pelo poder e a evolução do habitus nos séculos XIX e XX. Tradução de Álvaro Cabral. Rio de Janeiro: Jorge Zahar, 1997.

ELIAS, N. Sobre o tempo. Tradução de Vera Ribeiro. Rio de Janeiro: Jorge Zahar, 1998.

ELIAS, N. Teoria simbólica. $2^{\mathrm{a}}$ ed. Oeiras: Ceuta, 2002.

ELIAS, N.; DUNNING, E. A busca da excitação. Tradução de Maria Manuela Almeida e Silva. Lisboa: Difel, 1992.

ELIAS, N; SCOTSON, J. L. Os Estabelecidos e os Outsiders: sociologia das relações de poder a partir de uma pequena comunidade. Tradução de Vera Ribeiro. Rio de Janeiro: Jorge Zahar Editor, 2000.

FREITAS, M. C. de. História social da infância no Brasil. $5^{a}$ ed. São Paulo: Cortez, 2003.

GEBARA, A. Conversas sobre Norbert Elias: depoimentos para uma história do pensamento sociológico. $2^{\mathrm{a}}$ ed. Piracicaba: Biscalchin, 2005.

GINSBURG, K. R. The Importance of Play in Promoting Healthy Child Development and Maintaining Strong Parent-Child Bonds.American Academy of Pediatrics, v. 119, n. 1, p. 182-191, 2007.

KISHIMOTO, T. M. Jogo, brinquedo, brincadeira e a educação. $11^{\mathrm{a}}$ ed. São Paulo: Cortez, 2008.

KOURY, M. G. P. Emoções e Sociedade: Um passeio na obra de Norbert Elias. História: Questões \& Debates, Curitiba, v. 59, n. 2, p. 79-98, jul./dez. 2013.

LEITE, L. G.; FEIJÓ, J. P.; CHIÉS, P. V. Qual o gênero do brincar? Aprendendo a ser “menino”... Aprendendo a ser "menina”. Motrivivência. Florianópolis, v. 28, n. 47, p. 210-225, 2016.

LIRA, A. C. M.; NASCIMENTO, E. C. M. do. Infância e Contemporaneidade. In:LIRA, A. C. M.; NASCIMENTO, E (org.). Infância e Cultura. Curitiba: CRV, 2015.

MARCHI JÚNIOR, W. ; SOUZA, J. de. Norbert Elias e Pierre Bourdieu: tensões e conversações teórico-metodológicas no exercício de compreensão do mundo social. In: BOURGuignON, J. ; OLIVEIRA JÚNIOR, C. R. de. (org.). Pesquisa em Ciências Sociais: interfaces debates e metodologias. Ponta Grossa: Toda Palavra, p. 31-47, 2012.

MITRE, R. M. A.; GOMES, R. A promoção do brincar no contexto da hospitalização infantil como ação de saúde.Ciência e saúde coletiva, Rio de Janeiro, v. 9, n. 1, p. 147-154, 2004. 
SARAT, M. Contribuições de Norbert Elias aos estudos da infância e processo civilizador. In: GEBARA, A.; COSTA, C. J. ; SARAT, M. (org.). Leituras de Norbert Elias: Processo civilizador, educação e fronteiras. Maringá: Eduem, p. 157-174, 2014.

SARAT, M. Relações entre gerações e processos “civilizadores". In: GOETTERT, J. D.; SARAT, M. (org.). Tempos e espaços civilizadores: diálogos com Norbert Elias. Dourados: Editora da UFGD, p.103-119, 2009.

SCALHA, T. B. ; SOUZA, V. G.; BOFFI, T. ; CARVALHO, A. C. A importância do brincar no desenvolvimento psicomotor: relato de experiência. Revista de Psicologia da UNESP, v. 9, n. 2, p. 79-92, 2010.

SOUZA, J. de. O “esporte das multidões” no Brasil: Entre o contexto de ação futebolístico e a negociação mimética dos conflitos sociais. Curitiba, 2014, 433 f. Tese (Doutorado em Educação Física) - Setor de Ciências Biológicas, Universidade Federal do Paraná - UFPR, Curitiba, 2014.

SURDI, A. C.; MELO, J. P. de; KUNZ, E. O brincar e o se-movimentar nas aulas de educação física infantil: realidades e possibilidades. Movimento. Porto Alegre, v. 22, n. 2, p. 459-470, 2016.

TEIXEIRA, C. C. dos S. A Importância da Brincadeira no Desenvolvimento Cognitivo Infantil. Id on Line Revista Multidisciplinar e de Psicologia, v. 10, n. 33, p. 94-102, jan. 2017.

TOZZI, J. B. Educação, infância e leitura: contribuições da teoria dos processos civilizadores de Norbert Elias. Pro-Posições, v. 24, n. 2, p. 127-145, 2013.

VYGOTSKY, L. S. A formação social da mente: o desenvolvimento dos processos psicológicos superiores. São Paulo: Martins Fontes, 1994.

\section{NOTAS}

${ }^{1}$ Ao mencionar estudos na área da infância, não podemos deixar de enfatizar a importante contribuição do historiador Philippe Ariès, o qual foi um dos primeiros estudiosos a avançar em estudos na área da história social da infância, apresentando elementos importantes para a demarcação da criança na sociedade medieval e nos séculos seguintes. (Ver: ARIÈS, Philippe. História social da infância e da família. Tradução de Dora Flaksman. Rio de Janeiro: LCT, 1978.). No Brasil, destacam-se os empreendimentos de Marcos Cezar de Freitas, especialmente a obra História social da Infância no Brasil. (Ver: FREITAS, Marcos Cezar de. História social da infância no Brasil. 5. ed. São Paulo: Cortez, 2003.). Já na perspectiva configuracional vale destacar a contribuição de Magda Carmelita Sarat Oliveira, que tem avançado em estudos sistemáticos na área da infância, se utilizando das contribuições do referencial teórico de Norbert Elias. (Ver: SARAT, Magda. Contribuições de Norbert Elias aos estudos da infância e processo civilizador. In: GEBARA, Ademir; COSTA, Célio Juvenal; SARAT, Magda (org.). Leituras de Norbert Elias: Processo civilizador, educação e fronteiras. Maringá: Eduem, 2014. p. 157-174.).

${ }^{2}$ Quando falamos sobre o processo civilizador individual, estamos nos referindo ao processo constitutivo de formação do indivíduo dentro de suas configurações. Pois, embora, tenhamos um processo civilizacional em curso na sociedade, as formas e os níveis de adequação a esse meio são bastante diferenciados. Isto é, cada pessoa, por meio de suas relações de 
interdependência, constroem ao longo da vida um processo civilizador individual.

${ }^{3}$ A sociologia dos processos se refere ao modus operandi levado a cabo por Elias em seus empreendimentos, que considera os seus objetos em uma perspectiva de longo prazo e processual. Para o sociólogo, uma boa diagnose de um problema social se dá por meio da leitura do passado até o presente.

${ }^{4}$ Embora, ao longo do texto mobilizemos com intensidade a teoria dos processos, cabe aqui, mencionar que tal teoria foi desenvolvida na década de 1930 e apresentada nos dois volumes de "O processo civilizador". Se utilizando do seu laboratório empírico, os três países (Alemanha, França e Inglaterra), os quais tivera íntimo contato, Norbert Elias em uma investigação de longo prazo, desde a Idade Média até a modernidade, consegue verificar uma profunda mudança no tecido social europeu, tanto a nível sociogenético como psicognético. Nesse caso, a estrutura da personalidade das pessoas e do comportamento alterava em sincronia com as mudanças da sociedade e vice-versa.

${ }^{5}$ Importante sinalizar que ao recorrermos ao conceito de habitus, estamos se utilizado da concepção proposta em Elias. Embora, o conceito se aproxime em vários aspectos do modo com que essa noção é utilizada na obra de Bourdieu (Ver: MARCHI JÚNIOR, Wanderley; SOUZA, Juliano de. Norbert Elias e Pierre Bourdieu: tensões e conversações teóricometodológicas no exercício de compreensão do mundo social. In: BOURGUIGNON, Jussara; OLIVEIRA JÚNIOR, Constantino Ribeiro de. (org.). Pesquisa em Ciências Sociais: interfaces debates e metodologias. Ponta Grossa: Toda Palavra, 2012, p.31-47.) existem algumas diferenças fundantes, sendo que para Bourdieuo habitus tem uma dimensão mais estrutural e em Elias uma dimensão mais histórica. Para Bourdieu, o babitus funciona como matriz da ação social, formas de perceber, sentir, fazer, pensar, agir em determinado campo (BOUDIEU, 2003). Já para Elias o habitus diz respeito a autoimagem e composição social herdada de sua sociedade de origem e que marca, portanto, a identidade nós (ELIAS, 1994).

"O conceito "outsiders" é introduzido por Elias na obra "Estabelecidos e outsiders". Neste empreendimento em questão, o sociólogo faz uma leitura sociológica de bairros de uma pequena cidade na Inglaterra, identificando problemas de socialização entre esses bairros, cujos moradores mais antigos da cidade passam a se considerar superiores em relação ao grupo recém estabelecido, ou seja, esse aspecto gera um fator de distinção entre os grupos. Assim, aqueles que não pertencem ao território mais antigo, são os excluídos, o que Elias chama de "outsiders". Portando, esse termo é justamente utilizado para sinalizar o não pertencimento de uma pessoa ou grupo em determinado contexto. Para uma melhor compreensão do conceito de "outsiders", ver: ELIAS, Norbert; SCOTSON, John L. Os Estabelecidos e os Outsiders: sociologia das relações de poder a partir de uma pequena comunidade. Tradução de Vera Ribeiro. Rio de Janeiro: Jorge Zahar Editor, 2000.

${ }^{7}$ E segundo Elias, essa historicidade permeada pelas experiências do indivíduo singular desde a infância que é característica da composição biológica, inata e herdada dos seres humanos, que permite nos diferenciar de outras sociedades, como por exemplo a sociedade das formigas. Portanto, através de nossas experiências ao longo da vida, construímos uma "história” um "desenvolvimento social”. Ver: ELIAS, Norbert. Introdução: Sociologia e história. In: ELIAS, Norbert (org.). A sociedade de corte. Tradução de Pedro Süssekind. Rio de Janeiro: Jorge Zahar, 2001b.

${ }^{8}$ No livro "Mozart: Sociologia de um Gênio", Elias descreve a influência de resíduos da 
infância na vida de Mozart, que em alguns momentos o ajudaram, como também em outros contribuíram para a sua desestabilização enquanto indivíduo adulto. Por exemplo, a incompetência de Mozart e a indiferença para com o dinheiro, o levaram a inúmeras dívidas que repercutiram em um enorme choque de realidade em sua vida, sendo este desfecho, possivelmente causado por resíduos de infantilidade, já que quando criança o pai sempre tomara conta de tudo no que dizia respeito ao filho. Em contrapartida, o resíduo infantil atrelado a espontaneidade e a fantasia podem ter contribuído para que Mozart produzisse as composições musicais que fez. Nesse particular, a riqueza de sua imaginação musical eram também um resíduo de infantilidade (ELIAS, 1995, p. 122). Ver: ELIAS, Norbert. Mozart: Sociologia, de um gênio. Tradução de Sergio Goes de Paula. Rio de Janeiro: Jorge Zahar, 1995.

${ }^{9}$ Talvez a obra em que Elias discuta com maior intensidade a importância da linguagem na vida dos indivíduos é a "Teoria Simbólica", possivelmente um dos textos no qual também mais trata do desenvolvimento social e biológico das crianças. Ver: ELIAS, Norbert. Teoria simbólica. $2^{\mathrm{a}}$ ed. Oeiras: Ceuta, 2002.

${ }^{10}$ Quando utilizamos a ideia de camadas sociais, não estamos nos referindo a classes sociais, como o conceito é regularmente mobilizado, mas sinalizando que à medida que os indivíduos vão alargando as suas relações, mais experiências e aprendizados vão sendo agregadas à sua vida como camadas sociais. Esse conceito é utilizado por Elias na obra "Sobre o tempo". Além disso, no texto o sociólogo também fala de camadas psíquicas que compõe as pessoas, tais com a afetividade, a consciência moral e as pulsões, que também são aprendidas por meio da aprendizagem, sobretudo determinadas socialmente no exercício das relações sociais. Ver: ELIAS, Norbert. Sobre o tempo. Tradução de Vera Ribeiro. Rio de Janeiro: Jorge Zahar, 1998.

${ }^{11}$ É importante destacar que o conceito de mimese estabelecido em Elias tem relação com a ideia de catarse discutida por Aristóteles no contexto da arte. Em resumo, o filósofo grego, segundo Elias, foi um dos precursores na compreensão do problema da imitação, por meio de seu laboratório empírico da época, a saber, a tragédia grega. De acordo com Elias, a imitação da tragédia, encenada no teatro grego, levava as pessoas a um profundo envolvimento com a peça, de modo que o entusiasmo, a euforia, o medo e demais sentimentos eram externalizados de maneira coletiva. Por isso, Norbert Elias mobiliza essa noção em seu programa para sociologia do esporte e do lazer.

Submetido: $18 / 10 / 2017$

Aprovado: 24/01/2018

Contato:

Vinicius Machado de Oliveira

Universidade Estadual de Maringá (UEM)

Programa de Pós-Graduação Associado em Educação Física

Campus Universitário, Av. Colombo, n5790

Maringá | PR | Brasil

CEP 87.020-900 